\section{Marine networks}

\section{David G. Ainley}

Seabirds: Feeding Ecology and Role in Marine Ecosystems. Edited by J.P. Croxall. Cambridge University Press:1987. Pp.408. £30, \$59.50.

THE management of seabird populations has traditionally been the responsibility of wildlife agencies which, in general, almost entirely concentrate upon terrestrial and freshwater ecosystems. Although it is certainly appropriate that the island breeding sites of seabirds - which are in critical need of care and protection - should come under the purview of these agencies, equally important to the viability of seabird populations is the wise management of the marine food webs of which seabirds are a component. Marine ecosystems, however, usually come under the authority of fishery agencies, in which multi-species management is much talked about but is largely yet to be realized. As a result of this management dichotomy, seabird biologists have been waging an unofficial campaign for the past 15 years to try to bring marine birds to the attention of fishery managers and biologists.

The book under review is the second to appear as an outgrowth of this effort; its 'flavour' is virtually the same as that of Marine Birds: Their Feeding Ecology and Commercial Fisheries Relationships, edited by D.N. Nettleship et al., and published in 1984 by the Canadian Wildlife Service. The two books have a number of authors in common, which doubtless in part accounts for the similar flavour, but they are actually quite complementary and do not overlap in content. Marine Birds contains case studies and theoretical models of the dynamics of seabird food webs, whereas the new volume summarizes and reviews the available information on diet, foraging behaviour and interactions with marine processes. Together, the books provide an up-to-date overview of seabird foraging ecology and should interest wildlife and fishery managers, ornithologists and ecologists working on pelagic marine food webs.

In the present volume, the contribution by R.W. Furness on kleptoparasitism, its prevalence in seabirds and significance to them, is long overdue. G.L. Hunt, Jr and D.C. Schneider's account of scale-dependent processes, and how our perceptions of interactions of seabirds with their environment are a function of scale, should stimulate further research. Successful applications of this discussion are presented in chapters by Schneider et al. for the comparison of energy flux in shallow-water seabird communities of Bristol Bay and Georges Bank, and by R.T. Briggs and E.W. Chu for energy flux in the upwelling system off California.

The remaining contributions mainly review what and how much is eaten by certain seabird taxa (penguins, Procellariiformes, Pelecaniiformes and alcids) and faunas (Gulf of Alaska, Hawaiian Islands, California current, Humboldt and Benguela currents, and South Georgia). They contain much useful information, as do the articles on seabird flight (a component of foraging) and diving behaviour.

Information on what is known about seabird foraging ecology is now well summarized. Clearly, further progress will come mainly through studies of foraging energetics, diets outside the breeding season, diets relative to prey availability, and the relationship between foraging and population ecology.

David G. Ainley is Director of Marine Studies, Point Reyes Bird Observatory, Stinson Beach, California 94970, USA.

\section{Manufacturing the mental process}

\author{
John A. Campbell
}

Thinking Machines: The Evolution of Artificial Intelligence. By Vernon Pratt. Basil Blackwell:1987. Pp.254. £19.50, $\$ 19.95$.

ONE measure of the interest of a subject is the extent to which volunteers to write or otherwise explain its intellectual history turn up. For most subjects, this measure refers not only to interest but also to respectability. For some, including (unfortunately) artificial intelligence, the earliest volunteers have included science-fiction writers and cowboys. The pattern in these cases usually starts with a Wild West phase, in which a subject is long on public interest but short on respectability, followed by a period of inactivity on the intellectual-history front while instant applications are not forthcoming and while the specialists quietly get on with the work of consolidation and establishment of fundamental principles. If the second phase is a successful one, then the arrival of non-cowboy volunteers to describe the subject and its historical pedigree indicates that a period of combined interest and respectability has arrived with (or somewhat before) them.

The first person to attempt a thorough account of the historical development of artificial intelligence will have a difficult job because of the very wide range of material and possibilities that needs to be considered. This is an open challenge to professional historians of science. Until it is taken up convincingly, everyone is free to assemble his or her version of

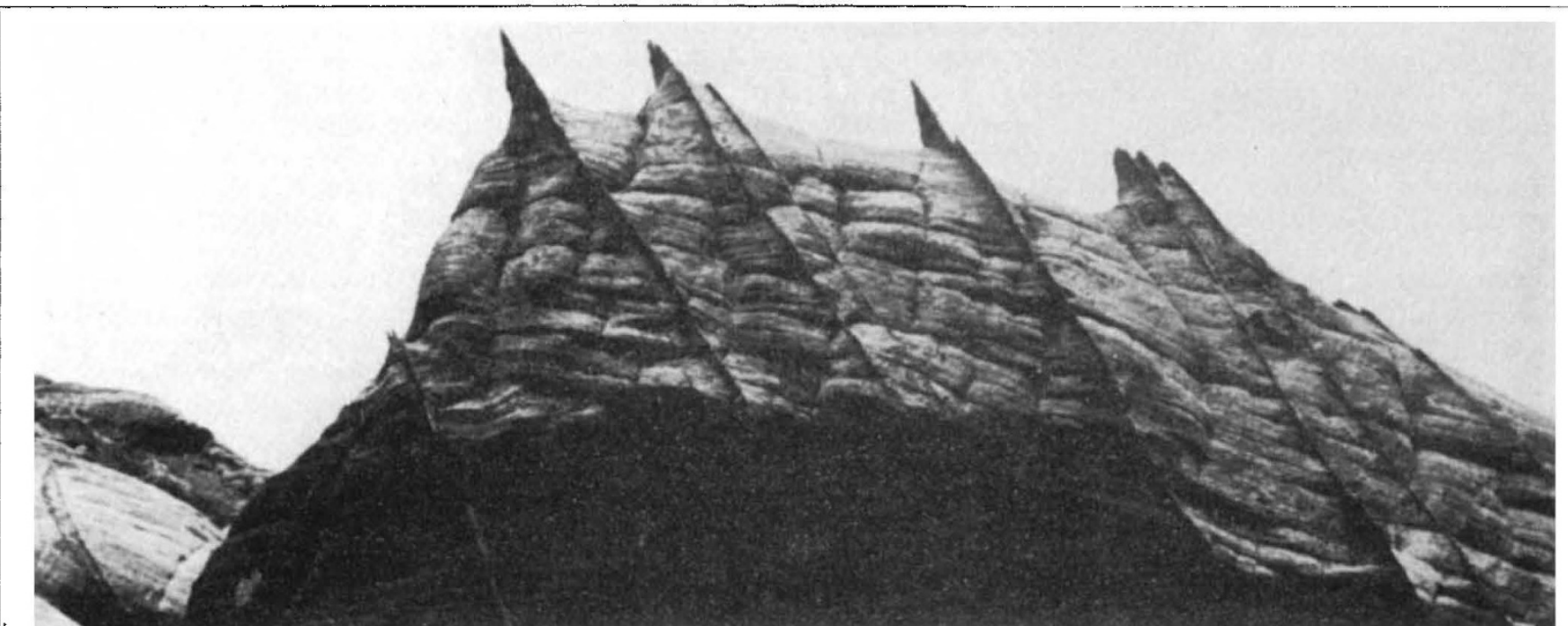

Jagged edge - this formation from the Valley of Fire in Nevada shows joints with walls impregnated with silica cutting across bedded sandstones. The picture is taken from The Techniques of Modern Structural Geology Vol. 2: Folds and Fractures by John G. Ramsay and Martin I. Huber. Vol. 1 won the Geological Society of America 1985 Best Paper Award. The book is published by Academic Press and costs £17.50, \$34.50. 